D) Check for updates

Cite this as: $B M J 2021 ; 374: n 2235$ http://dx.doi.org/10.1136/bmj.n2235

Published: 13 September 2021

\section{Proposed takeover of Vectura by Philip Morris International}

We misspelt Philip Morris in this editorial by Sanjay Agrawal (BMJ 2021;374:n2186, doi:). The online version has been corrected. 